\title{
KÜLT VE KÜLTÜR ARASINDA: YENİ BİR KÜLT TANIMLAMASINA DOĞRU ${ }^{*}$
}

\author{
BETWEEN CULT AND CULTURE: TOWARDS A NEW CULT IDENTIFICATION
}

\section{Kübra YILDIZ ALTIN**}

ÖZ: Bilimsel çalışmaların ilk basamağında yer alan terminoloji, aynı şeyleri farklı terimlerle ifade etmeyi önleyen ve bu sayede anlașma ortamı sağlayan bir alan bilgisi sunar. Bu açıdan terminolojiye hâkim olmak, aynı zamanda, alan bilgisine hâkim olmak anlamına gelmektedir. Her bilim alanında olduğu gibi sosyal bilimler alanında da terminoloji zaman ve mekâna bağlı olarak kendini güncellemekte ve yeni kavramlar eklenmektedir. Sosyal bilim alanı içinde yer alan mit biliminde de bu güncellemeler yapılmaktadır. Türk mit biliminde halen üzerinde fikir birliği sağlanamamış bazı terimler bulunmaktadır. Bunlardan biri olan "kült" terimi, günümüze kadar teolojik bir bakış açısı içinde değerlendirilmiştir. Ayrıca buradaki mevcut kült tanımlamaları "bağlamı" göz ardı etmektedir. Bu bakış açısı ise kült ile ilgili olarak "tapma ve/veya ibadet” karşılıklarının kullanımını yaygınlaştırmış durumdadır. Dahası bu tür tanımlamalar, mit araştırmaları bağlamında, alanı temsil kabiliyetine sahip değildir. Kült için verilen karşılıklar, kültün meydana geliş sürecini anlama noktasında da yeterli bir açıklama sağlamamaktadır. Dolayısıyla Türk mitolojisinde yeni bir kült tanımlamasına ihtiyaç vardır. Söz konusu eksikliğin giderilmesinin amaçlandığı ve külte ilişkin yeni bir tanımlamanın önerildiği bu çalışmada kült, öncelikli olarak, kullanıldığı bağlama göre değerlendirilmiș, ardından külte yapısal ve işlevsel açıdan yaklaşılmıştır. Bu değerlendirmeler ve yapısal işlevselcilik temelinde yapılan sorgulamalar, kült ve kültür arasında bir ilișki olabileceğini ortaya çıkartmıştır. Çalışmada ele alınan bu ilişki aracılığıyla "kültürün kült(sel) kökenleri" tespit edilebilmiştir. Bu süreçte literatürdeki kült tanımları incelenmiş, konuyu tartışmaya açacak bir biçimde ve mit araştırmalarında kullanılmak üzere yeni bir kült tanımlaması önerilmiştir. Son olarak kültün mit bilimi araştırmaları -ve hatta günümüz kültür çalışmalarıiçin önemi ortaya konulmuştur.

Anahtar Kelimeler: Türk mitolojisi, kült, kültür, kültten kültüre, yapısal işlevselcilik.

ABSTRACT: Terminology in the first step of scientific studies prevents the expression of the same objects in different terms and in this way, a field information that provides an environment of agreement presents. To dominate terminology also means dominating the field knowledge. However, terminology provides an opportunity to help prevent conceptual clutter in field knowledge. As in every field of science, the terminology of the social sciences is updated in time and space and new concepts are added. These updates are also made in the mythology within the field of social science. There are still some terms in Turkish mythology that have not been

\footnotetext{
* Bu çalışma, Hacettepe Üniversitesi, Sosyal Bilimler Enstitüsü, Türk Halkbilimi Anabilim Dalında hazırlanmış olan "Türk Kültüründe Atalar Kültü" başlıklı doktora tezinden üretilmiştir. Yürütücülügü Prof. Dr. Özkul ÇOBANOĞLU tarafından yapılan bu tez, TUBİTAK 2211A-Yurt İçi Doktora Bursu kapsamında desteklenmiştir. Desteklerinden dolayı TÜBITAK'a teșekkür ederim.

** Arș. Gör. Dr. - Nevşehir Hacı Bektaș Veli Üniversitesi Fen-Edebiyat Fakültesi Türk Halkbilimi Bölümü / Nevşehir - kubrayildiz89@gmail.com
}

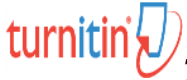

This article was checked by Turnitin. 
agreed upon. One of them is the cult term and it has been evaluated from a theological perspective until today. Also, it is seen that the current definitions of cult in Turkish mythology ignore the "context". This point of view has expanded the use of "worship and/or prayers" provisions in relation to cult. Moreover, such definitions are not capable of representing the area in the context of myth research. Provisions for cult do not provide an adequate explanation for the understanding of the occurrence of cult. Therefore, a new cult definition is needed in Turkish mythology. In this study, the said deficiency was tried to be eliminated and a new definition of the cult has been proposed. In the study, the cult was evaluated primarily according to the context in which it was used, and then it was approached structurally and functionally. As a result of these evaluations and inquiries on the basis of structural functionalism, it was found that there might be a relationship between cult and culture. "The cult(ic) origins of culture" could be determined through this relationship in the study. In this process, the definitions of cult in the literature were examined. Then, it was proposed to define a new cult to be used in myth researches and to open the subject to discussion. Finally, the importance of the cult for mythology research -and even for today's cultural studies- will be revealed.

Keywords: Turkish mythology, cult, culture, from cult to culture, structural functionalism.

\section{Giriş}

Sosyal bilimlerde bazı kavramlar kullanıldığı bağlama göre farklı anlamlara gelebilmektedir. Bunlardan biri olan kült, teolojiden sosyolojiye kadar neredeyse hemen her beșerî bilim dalının konu alanı içinde kullanılmıştır. Mitoloji araştırmaları bağlamında kültün yeni bir tanımının önerildiği bu çalışmada ise kült ve kültür arasındaki ilişki ele alınmış ve bazı temel sorulara yanıtlar aranmıştır. Birkaç soru şu şekildedir:

Kült ve kültür arasında bir ilişkiden bahsedilebilir mi? Kültürün şekillenmesinde kültlerin var mıdır? Kültten kültüre ve/veya kültürden külte bir geçişten bahsedilebilir mi? Bu sorular bağlamında kültün neyi temsil ettiği ve kültürün neresinde olduğu sorusu tartışmaya açılmıştır. Kültün ne olduğunun sorgulanması ise inancı külte dönüştüren yapının ele alınmasını beraberinde getirmektedir. 0 halde neden her inanış unsuru kült sınıfı içine gir(e)mez veya kült içinde değerlendiril(e)mez? Bu durumda hangi inanış unsurları, nesneler veya şey'ler kült içinde değerlendirilir?

Günümüz Türk mit bilimindeki "mevcut" kült tanımlarının alanı temsil kabiliyetine sahip olmaması, külte ilişkin yeni bir tanımlamaya ihtiyaç olduğunu göstermektedir. Teoloji ve mitoloji araştırmalarında sıklıkla geçen kült kavramına mekân, zaman, inanç unsuru başta olmak üzere "bağlam" dikkate alınarak bakıldığında, kültün insanoğlunun yaşamına ilişkin maddi, manevi ve sosyal işlevlerinin olduğu ortaya çıkmaktadır. Bu noktada yapıyı ve işlevi, diğer bir deyişle, "bağlam"ı temel alan kuramsal yaklaşımlardan biri olan "yapısal işlevselcilik", kültü ve kültten kültüre geçişi anlama ve açıklama konusunda önemli veriler elde etmemize imkân tanımaktadır.

Bağlama dikkat çeken ve işlevi vurgulayan Malinowski (1990: 97-98) "bir öykünün entelektüel karakteri metniyle sınırlıdır, oysa ilkellerin her öyküsünün işlevsel, kültürel ve faydacı yanı, metinde olduğu kadar öykünün anlatılışında, cisimlenişinde ve içeriksel bağlamında da kendini gösterir." 
diyerek, bağlamın öneminde dikkat çekmektedir. Dolayısıyla mit araştırmaları içinde sıklıkla geçen kültleri anlamak ve yorumlayabilmek için neredeyse her dönem anlam değişikliğine uğramış veya anlam alanı genişlemiş olan kültü yeniden ele almak gerekmektedir.

Hemen her sosyal bilimci, içinde bulundukları kültürel yapı sebebiyle kültü farklı yorumlamışlardır. Dolayısıyla kültün hangi bağlamda açıklandığını ve onun kültürün hangi katmanına yerleștirildiğini bilmek oldukça önemlidir. Kullanıldığı bağlama göre farklı anlamlar kazanan külte ilişkin olarak kültün Batı dillerinde verilen karşılığı dikkate alındığında teolojik bir bakış açısı temelinde "tapım, tapma veya ibadet" şeklinde yaygın bir tanımlama olduğu görülür.

Özellikle mitoloji alanındaki çalışmalarda kült, doğrudan "tapım", "kutsama" ve "ululama” ile ilişkilendirilmiştir. Bu genel eğilimin kaynağı, arkeolojik çalışmalara kadar götürülebilir. Örneğin arkeolojik çalışmalarda ${ }^{1}$ kült, özellikle antik eserler için kullanılmaktadır. $\mathrm{Bu}$ alandaki çoğu araştırmacı ise "ilkel" olarak nitelendirilen insanların söz konusu antik eserlere taptıklarını düşünmüşlerdir. Bu yüzden kült terimi, günümüze kadar "tapma" ve "ibadet" ile ilişkilendirilmiştir. Bu ilişkilendirmelerde kült, "yüce ve kutsal olana tapma" (Akyurt, 1998: 154) anlamında kullanılmıştır.

Mit araştırmalarında kült terimi ne kadar az tartışılmışsa, din çalışmalarında da o derece fazla ele alınmıștır. Dolayısıyla kült konusunda yapılacak literatür taramasında ilk başvuru kaynakları din, dinler tarihi ve din sosyolojisi alanında olmaktadır. Günümüzün din çalışmalarında kültle ilgili olarak tercih edilen terimler "yeni dinî hareketler", "alternatif dinler" ve "azınlık dinleri" șeklinde sıralanabilir (Edwards, 2018). Bu sıralamada "çoğunluğun içinde belli bazı nitelikleriyle ayrılan ve yine aynı çoğunluk tarafından öteki olarak kabul edilen küçük (dinî) grup” düşüncesi ortak özellik olarak yer almaktadır.

Dinî kültleri inceleyen Pavlos (1964: xv) kültleri tamamen anlayabilmek için yeni dinî oluşumları ve onların toplum üzerindeki etkilerinin incelenmesi gerektiğini iddia etmektedir. Bu bakımdan dinî kültleri ele alan çalışmalarda yeni dinlerin nasıl ortaya çıktıkları, köklerini aldıkları oluşumlar, bu dinî grupların (örn. mesih gibi) liderleri (programmer) ve takipçileri etkileme biçimleri gibi belli başlı konulara cevaplar aranmaktadır. Özellikle takipçileri etkileme veya "yeniden eğitme" (deprogramming) biçimlerinde "ters beyin yıkama" (reverse brainwashing) ve "zihin kontrolü" (mind control) yöntemlerinin nasıl uygulandığı öncelikli

\footnotetext{
${ }^{1}$ Arkeolojide din konulu çalışmalar son yıllarda artış göstermektedir. Bu kapsamda arkeolojik verilerden yararlanılarak eski inanç sistemlerini anlamaya yönelik çalışmalar yapılmaktadır. Özellikle ritüeller, bu türden çalışmalara yeni dâhil edilen alanlar arasındadır. "Kült ve Din Arkeolojisi" (Archaeology of Cult and Religion) adı altında yapılan araștırmalarda, ritüellerin arkeolojik göstergelerinin dikkate alındığı görülmektedir (Insoll, 2005: 47). Söz konusu incelemelerde elde edilecek sonuçların mitoloji araştırmalarına katkı sağlayabileceğini söylemek mümkündür.
} 
olarak ele alınan konular arasındadır. Dinî bir grup olan kültlere katılım konusunu araştıran bu tür çalışmalarda, katılımın sebeplerini sosyal, psikolojik, ruhsal/manevî ve ekonomik dinamiklere bağlamanın yanı sıra psikopatoloji (psychopathology) ile ilişkilendiren incelemeler de vardır (Collin, 1982).

Özellikle sosyolojide kült, kullanım alanını genişletmiş ve farklı anlamlar kazanmıștır. Bu bağlamda kültün mekân, zaman ve hatta toplumlara göre anlamı değişmiştir. Özellikle batılı bilim adamları arasında kültün sosyolojik ve daha özelde din sosyolojisi içindeki anlamı tartışılmıştır. Bu noktada Richarson'un (1993: 349) kült tartışmaları veya kültün anlam alanının genișliği konusunda ortaya koyduğu tespit dikkate değerdir: "Bir toplumun bireysellik ve rasyonelliğe hâkim bir değeri varsa, o zaman kültle ilişkili cevaplar bireysel-mistik, kolektivist-rasyonel veya kolektivist-mistik olabilir". Bu cümleden kültün, yer aldığı bağlama göre anlamının farklılaştığını; pozitif, negatif veya nötr bir anlam kazandığını söylemek mümkündür².

Literatürdeki kült tanımları içinde yaygın olarak "saygı duyma, kutsama, kendini bir şeye adama, ululama, yüceltme" anlamları görülür. İster arkaik isterse modern örneklerden yola çıkılsın kültte "bağlılık duyma ve bağlllık duyulanlar için kendini diğerleri içinde ayırt etme" veya "biz ve onlar" bileșimi söz konusudur ${ }^{3}$. Özellikle son dönem yapılan feminizm

2 Günümüz araştırmacıları yeni dinî oluşumların ortaya çıkışını açıklamaya kültlerden başlamaktadır. Son yıllarda kült terimine dikkat çeken grup, başlıca din sosyolojisi üzerine çalıșan araștırmacılardır. Bu çalıșmalarda bazı gruplar kült terimi üzerine odaklanırken, bazıları kült fenomeninin olușumu üzerinde çalıșmıșlardır. Özellikle din sosyolojisi alanında ve sosyal bilimlerin diğer alanlarında yaygın bir biçimde kullanılan kült terimi kısa zamanda büyük çeșitlenmeler yașamıștır. Terimin, toplumsal yapıdaki lehte görülmeyen gruplara karşı kullanılmasında -Richardson'un (1993: 352) ifadesiyle- "sosyal bir silah" haline gelmesi ve özellikle medyanın onun "çoklu anlamlarını" ayırt etmeden kullanması, kült karșıtı hareketlerin (Anti-Cult Movement) fitilini ateșlemiștir. Kült karşıtı hareketler hakkındaki bu çalıșmalar için bk.: (Barker, 1986; Sandwith, 2004; Shterin and Richardson, 2000; Swantko, 2000; Yoshihide, 2000). Söz konusu araştırmalarda kült terimi "yeni dinî hareketler" (New Religious Movements) (NRMs) anlamında kullanılmıștır. Bk.: (Collin, 1982; Davis, 1996; Faulkner, 1996; Ibrahim, 2013; Neal, 2011; Olson, 2006; Panchenko, 2004; Richardson, 1979). Bu hareketlerde daha çok beyin yıkama (brainwashing) ve zihin kontrol (mind-control techniques) tekniklerinin kullanıldığı bilinmektedir (Collin, 1982). Bu dinî hareketler bağlamındaki kült tipolojisi üzerine yapılan bir çalışma için bk.: (Nelson, 1969).

Kült terimiyle ilgili son çalışmalar arasında kültlerin doktrinleştirme süreçleriyle bağlantıları da ele alınmıștır. Bk.: (Davis, 1996; Pfeifer, 1992).

Dinî sistemlerde kültlerin ideolojik kullanımını temel alan ve bu bağlamda "cult centralization" kavramı üzerinde odaklanan bir çalışma için bk.: (Lowery, 1991).

3 İster klasik isterse modern kült tanımlamaları takip edilsin, hemen hepsinde görülen ortak özellik bir kültür unsurunun -bu bazen bir grup, bazen bir inanıș, bazen bir maddî nesne olabilir- "belli bazı özellikleriyle diğerlerinden ayrılma" durumudur. Örneğin, XVI. Yüzyll Roma Katolikliği, Protestan Reformcularının, Roma'nın "resmî" öğretilerini saptırdıklarında bir kült oluşturduklarını iddia edeceklerdi (Edwards, 2018). Dolayısıyla devletin resmî dini karşısında çoğu zaman tehdit olarak gördüğü her tür diğer inançsal 
temelli çalışmalarda bu değerlendirmeyi görmek mümkündür. Bu tarz çalışmalarda (azınlıkta olan) feminenlikteki kült potansiyelin (çoğunlukta olan) eril bir kimlik tarafından oluşturulduğu düşünülmektedir. Söz konusu cinsiyetlendirilmiş kült inşasında (gendered construction of cult) gelişen kült duyarlılığının içerik ve mekân üzerindeki eril ustalık duygusu ile şekillendiği (Och, 2019: 217) kabul edilmektedir. Ancak bu tanımlamalar yapılırken kültü bağlamı içinde değerlendirmek oldukça önemlidir. Bu noktada kültü birkaç tanım altında toplamak mümkündür: marjinal veya gayri resmî olarak görülen din (bu dinin ayrıca bir taraftar kitlesi vardır); bir kişiye, düşünceye, nesneye veya harekete büyük bağlılık; bir dinî inanç ve ritüel sistemi (Yunan mitolojisindeki Tanrı Apollo kültü gibi); ibadet-ritüel, duygu, ayin ve tutumla ilgili her şeyi ifade eder; tapma, tapınma; dinî kutsama; üreticisi/tanıtıcısı tarafından bir sisteme bağlı şekilde oluşturulan hastalık tedavisi için yöntem/sağlık kültleriं ${ }^{4}$ (Halton, 2014: 65; Larson, 1983: 27; Seymour-Smith, 1987: 61).

Kült kavramının bugünkü bazı çalışmalarda "fetişleşme" olarak kullanıldığı görülmektedir. Örneğin, günümüz iş gücü piyasasında hemen her sektörün "deneyim" şartını koyması ve iş verenlerin bu standardın dışına çıkmamaları davranışı Holdsworth (2015: 2) tarafından "deneyim kültü" (the cult of experience) veya deneyim fetişleşmesi (the fetishizing of experience) şeklinde kavramlaştırılmıştır. $\mathrm{Bu}$ ise geç veya post-modern toplum olarak tanımlanan günümüz yaşam tarzının iş gücü piyasasındaki deneyim istemeye ilişkin tutkulu veya ısrarlı tavrı tanımlamada kullanılmıştır.

Tanımlamalardan görülebileceği üzere kültün kullanım alanı oldukça geniștir. Kültürle aynı kökeni paylaşan kült teriminin zamanla kullanımının değiștiği ve anlam genişlemesine uğradığı söylenebilir. Bununla birlikte bazı araştırmacılara göre kült deneyiminin incelenmesi, insan beyninin işleyişi hakkındaki teoriler için önemli çıkarımlara sahiptir (Collin, 1982). Bu noktada gerek sosyoloji gerekse mitoloji bağlamındaki kült araştırmalarında "bütüncül" bir bakış açısının benimsenmesi gerekmektedir5.

gruplaşmaları "öteki” olarak tanımlaması, bu gruplaşmaları, modern tanımlamalarda kast edilen kültün veya sectin içine dahil etmeye yeterli olmuştur.

4 Sağlık kültleri alanında "ergoterapi" veya "iș terapisi" örnek olarak verilebilir. Dünyadaki endüstriyel iş eğilimleriyle beraber artış gösteren sağlık ve terapi uygulamaları, folklorik yönden incelendiğinde, bunların kültik ve ritüelistik birtakım nitelikler barındırdığı görülmektedir. İş terapistlerinin kendi ortak inanç ve değerlerine göre hareket etme istekliliği, kuşaktan kuşağa aktarılan teknik ve bilgilerin oluşmasını sağlamıștır. Bu sürecin "iş terapi miti" yarattığını düşünen bazı kültür bilimciler, buradaki mitlerin kültürel kimlik duygusu yaratan bir dizi ortak felsefi varsayımdan ortaya çıktığını düşünmektedirler. Daha ayrıntılı bilgi için bk.: (Kelly and McFarlane, 2007). Bu bağlamda iş terapisine katılan kișinin durumu, mitik kahramanın sonsuz yolculuğuyla (inisiyasyon) ilișkilendirilebilir ve/veya iş terapistiyle ilgili mitler, kahraman veya atalar kültü temelinde incelenebilir.

5 Bütüncül bir bakış açısı ile konuya yaklaşmak disiplinler arası çalışmayı beraberinde getirmektedir. $\mathrm{Bu}$ konuda inkübasyon ritüelinde kişisel iyileşme deneyimlerini destekleyebilecek olan Asclepius kültüne bilişsel bir yaklaşım öneren ve Panagiotidou 
Sonuç olarak, sosyal bilimler alanında yapılan çalışmalardaki kültün bilinen ilk kullanımlarında "ibadet" ve "tapma, tapım" karşılıkları verilmiștir. Daha sonraki zamanlarda terim, "seküler" bir içerik kazanmış ve kült için "dinî olmayan bir kişiye, düşünceye veya herhangi bir șey'e bağlllık" anlamları getirilmiştir. Bugün içinse kültün dinî ve din-dışı anlamlarıyla kullanılmaya devam ettiğini söylemek mümkündür.

\section{2. İnanıştan Külte: Kalıplaşma, Varyantlaşma, Gelenekselleşme}

Kültleşmeye başlayan inanışların tam bir kült seviyesine erişmesi "kalıplaşma", "varyantlaşma" ve "gelenekselleşme" aşamaları ile gerçekleşir6. Bu bağlamda kültün meydana gelişinde "inancın kristalleşmesi"7 büyük önem taşımaktadır. Bu bağlamda modern çağda kadim kültler ve onların mitleri, önceden belirlenmiş bazı standartların devamını sağlar. Köklerini kadim gelenekten alan XXI. Yüzyıldaki kültlerin bu imge ve anlatıları ise teknoloji çağının ortasındaki takipçileri ruhî bir dünya içine çeker (Larson, 1983: 18).

İnanış unsurlarında kalıplaşma süreci ise neredeyse bir zorunluluktur. Aksi takdirde bu unsurun gelenekte yaşamını devam ettirmesi mümkün değildir. Dinin gelişiminde kültün önemine vurgu yapan Harrison'un belirttiği gibi (1913: 155) "kutsal kişiler, kendi kültlerine sahip olabilirler veya kült belli bir yere bağlanabilir, geniş bir alanı kaplayabilir, bir kişi veya nesne ile sınırlanabilir. Fakat hiçbir yerel kahraman, kültü olmaksızın yaşamını devam ettiremez." Dolayısıyla kült, sadece tarihsel süreç içinde gelişmiş bir olgu değil, aynı zamanda sürecin bir gerekliliğidir.

"Varyantlaşma", merkez etrafındaki çevrenin genişlemesi, farklılaşması veya değişmesi olarak ifade edilebilir. Bu sayede kalıplaşmalar içinde çeşitlenmeler görülür. İnançlarda sürekli bir çeşitlenme söz konusudur. $\mathrm{Bu}$ bağlamda "mitik temaların çağdaş olaylarla ilişkileri aracılığıyla canlandığını" (Sered, 1995: 139) söylemek mümkündür. Aynı zamanda bu canlanma, varyantlaşmayı beraberinde getirir8.

(2016) tarafından yapılan bir çalışma örnek verilebilir. Bilişsel yaklaşımların Asclepius kültü üzerindeki tarihsel bilgiyi nasıl zenginleștirdiğinin gösterilmeye çalışıldığı bu araștırma, hayatta kalma ve refah hedefine yönelik çeşitli inanç ve eylemleri paylaşan antik Yunan dünyası insanlarının çoklu deneyimleri hakkında önemli bilgiler sağlamaktadır. Söz konusu çalışmaya göre Asclepius tapınaklarındaki iyileşme olasılığı, hastaların plasebo tepkilerinin potansiyel bir sonucudur.

6 İnanışın külte dönüşmesi ile ilgili üç bileșen, sayın Prof. Dr. Dursun Yıldırım’ın “Türk Folklor Araștırmalarının Problemleri" adlı makalesinde folklorun mahiyetiyle ilgili kaleme aldığı beş özellikten (Sözlü Olma, Geleneğe Bağlılık, Çeşitlenme, Anonimlik, Kalıplaşma) hareketle oluşturulmuştur. Daha ayrıntılı bilgi için bakınız: (Yıldırım, 1991).

7 Bu tanımlamada esin kaynağı "kült kristalleşmesi süreci" (process of cult crystallization) düşüncesidir. Bk.: (Sered, 1995: 104). Aynı yazıda, ayrıca, Rachel kültünün gelişimi ve "proto-cult" hakkında bk.: (Sered, 1995).

8 Sered'in (1995) ifade ettiği bu “canlanma"yı, Wallace'in (1956: 270) "yeniden canlandırma hareketi" (revitalization movement) kavramlaștırmasıyla genişletmek mümkündür: "Daha tatmin edici bir kültür inşa etmek için toplum üyeleri tarafından kasıtlı, örgütlü ve bilinçli 
"Gelenekselleşme", kendi içinde doğal olarak kendi kendini yeniden üretme mekanizmaları taşır. Taşınan bu mekanizmalar, gelenekselleşen ve doğal olarak kalıplaşan bir olgunun olağan bir durumu ve sürecidir. "Gelenek adayları", zamanı geldiğinde geleneklere dönüşmemişlerse (takipçi bulamaması; işlevselliğinin olmaması veya işlevselliğinin kaybedilmesi veya anlamını yitirme), kendilerini ortaya çıkaran durumla birlikte ölürler. Gelenek adayları, böyle bir durumda ya ortadan kaybolurlar ya da yeniden üretim yapıldığı takdirde gelenek olarak yaşamaya devam ederler (Shils, 2003: 106, 129-130).

"Bir kuşaktan diğerine nakil yoluyla geçen gelenek parçacıkları, gerçekte, birbiriyle bağlantılı daha geniş parçalar ağının bir parçası" (Shils, 2003: 107) olup, bunların incelenmesi "geniş parçalar ağının" anlaşılmasına katkı sağlayacaktır. Bu bağlamda, kült ve kültür arasındaki ilişkinin yanı sıra kültü tanımlamaya çalışan bu inceleme, aynı zamanda, geleneklerin oluşumunun açıklanmasına katkı sağlayabilir.

\section{Kült ve Kültür Arasında veya Kültten Kültüre}

Her disiplinin kültürü kendi bağlamına göre yorumlamasının sonucunda birden fazla tanım ortaya çıkmıştır. Kroeber ve Kluckhohn'un [1952] döneminde yapılan kültür tanımlarını altı temel başlıkta sınıflandırmalarından ${ }^{9}$ buna yana kültür için verilen karşılıklar halen çeşitlenmeye devam etmektedir.

Genel olarak "semboller bütünü" biçiminde ifade edilebilen kültür, yine sembolleri aracılı̆̆ıyla iletişim ortamı yaratır. Bu iletişim ortamı içindeki ortak inançlara dayalı davranışların (Edara, 2017: 277) en eski izleri ise kültler aracılığıyla takip edilebilir. Teoloji temelli kültür tanımlamalarında da hâkim olan bu bakış açısı, "kültür"ün kaynaklarından birini dinî birtakım inanış ve uygulamalarla açıklamaya çalışan yaklaşımlarla paraleldir. Bu paralellik, "kült"ün en arkaik ve teolojik tanımlamalarında "ibadet etme" veya "tapma" karşılıklarının verilmesinin de arka planında bulunmaktadır. Din olgusunu kültürel bir sistem olarak değerlendiren yaklaşımlarda da benzer bir bakış açısı görülmektedir. Dini, "hareket eden semboller sistemi" şeklinde tanımlayan bu çalışmalarda din, "varoluşun genel düzeninin kavramlarını formüle eden bir yapı" (Geertz, 1973: 89) olarak kabul edilir. Bu tanımlamalar, aynı zamanda, kültü bir tür "şablon/model (pattern)" olarak açıklayan çalışmalarla paralel olup bu yaklaşımlarda kültün kültüre yaklaştırıldığını ifade etmek gerekir10.

çabalar" olarak tanımlanabilen bu hareket, davranışsal birlik kurar. Ayrıca bu tür hareketler, karakter olarak dinîdir.

9 Bunlar "betimleyici (sosyal hayatın toplamı)", "tarihsel (sosyal gelenek, aktarılan miras)", "normatif (kurallar, değerler)", "psikolojik (iletişim biçimi, uyum, öğrenme, ihtiyaçları karşılama)", "yapısal (soyutlama)" ve "genetik (insan eseri, kuşaklar arası aktarımın sonucu, sembol)" şeklinde sıralanabilir (Winick, 1957: 145).

${ }^{10} \mathrm{Bu}$ konuda daha ayrıntılı bilgi için bk.: (Buss, 1964). 
Mit dünyası, bir toplumun en geleneksel "toplum haritaları" olup insan, yaşam ve tabiata dair işlenmiş "kültürel kodları" (Çobanoğlu, 2001: 7) içinde barındırır. Söz konusu kültürel kod birimlerinden bir kısmını kültler karşılamaktadır. Bu noktada "sembollerle şekillenip tarihsel olarak aktarılan bir anlamlar örüntüsü yaratan kültürün" (Geertz, 1973: 89) sembolik oluşumlarının kaynakları, mit bilimi içindeki kültlerde bulunabilir.

İnsanlığın avcı ve toplayıcı dönemlerinde doğadaki insanın yaşamını sürdürmesi ve hayatını idame ettirmesi için bu vahşi doğayı evcilleştirmesi, yani ihtiyaçlarına göre (yeniden) düzenlemesi gerekmiştir. Kült düşüncesi, bu ihtiyacın en ilksel biçimlerinden birisidir. Çünkü kült, onu kapsayan mitten sonra, insanın evreni anlamlandırma çabasının bir ürünüdür. Buna paralel olarak kültür de evrenin insanoğlu tarafından anlamlandırılması, tanımlanması, düzenlemesi ve en nihayetinde doğanın evrimleștirilme süreçlerinin tamamlanması sonucunda meydana gelmektedir. Bu bakımdan bir toplumun ihtiyaç giderme pratikleri (yöntem ve teknikleri); doğayı anlaması ve anlamlandırması; doğayla anlaşması; sorunları çözümlemek ve zıtlıkları azaltmak için kullandığı uygulamaların tamamı, aynı zamanda onun kültürünün parçalarını bir araya getirmektedir.

İnsanların maddî ve sosyal ihtiyaçlarının yanında gelişen manevî ihtiyaçları, birtakım inanışları ve bunlara bağlı uygulamaları beraberinde getirmiştir. Ancak günümüzdeki inanış ve uygulamaların kökenlerine ilişkin açıklamalar unutulmuştur. "Dünyadaki birçok halkın edebiyat tarihlerinin, söz sanatlarının ve manevî miraslarının mitlerle başlatılması" (İbrayev, 2005: 357) aslında kültürün kaynağının kült, ritüel ve bunlara ilişkin anlatılar olduğu fikrini güçlendirmektedir. Ancak "rasyonel" kültür kuramcılarının bugün yaptıkları tanımlamalarda kültürün kült kaynağı görmezden gelinmektedir. $\mathrm{Bu}$ yüzden "kültü kültüre geri koymak zorundayız!" (Halton, 2014: 63).

İnsanoğlunun karşılaştığı zorluklara çözüm üretme, karmaşayı çözümleme, anlaşılmazlıkları anlamlandırma, zıtlıkları azaltma ve doğa ile uyum kurma yöntem ve teknikleri temel olarak maddî, manevî ve sosyal ihtiyaçlara karşılık gelerek kültürleri üretmiştir. Mekân, zaman, yaşanan olaylar kısacası bağlamın önemli olması dünyanın hemen her yerinde farklı ve kendine özgün bir kültür meydana getirmiştir. Kült ile ilgili olarak da benzer bir durum söz konusudur. Kült seviyesine ulaşan bir inanıșın

Kült ve kültürü birbirine bağlı ancak uzlașmaz karşıtlar olarak gören araștırmacılar da vardır. Taubes'e göre antik veya en azından daha eski mit ve kült biçimlerinde yer alan enerji veya güçler, özel tarihsel göstergelerinden çok daha uzun yaşarlar ve bu yüzden bugün bizimle birlikteler. Ona göre bu uzlaşma veya bir tarafın kazanımı hiçbir zaman gerçekleşmeyecektir. Bu bir geçiş olup "yeni", "eski" ile diyalektik bir gerginlikte var olacaktır (Miscall, 2011: 98-99). 
yaşamasında özellikle mekânla birlikte "anlatıcının ve dinleyicinin" yani bağlamın etkisinden bahsetmek gerekir ${ }^{11}$.

Kültürün maddî ve özellikle manevî taraflarına dikkat çekilmesi, en arkaik anlamlandırma çabaları olan kültler hakkında bilgi elde etmeyi sağlayabilir. Örneğin, külte bağlı ritüellerin (Nevruz) gerçekleştirilmesi için düzenlenen özel mekânlar (dağ tepesi veya su kenarı), kültürün maddî boyutunu oluştururken; kült etrafında oluşan inanışlar (mevsime bağlı tören olan Nevruz kutlaması ile tinsel arınma), kültürün manevî tarafını oluşturmaktadır.

Kültür, biyolojik olarak aktarılamadığı için bazı "yardımcılara" ihtiyaç duyar. Bunu mümkün kılan en önemli aracılardan birinin kültler olduğunu söylemek mümkündür. Kültürel belleğin ve sözün hâkim olduğu bir ortamda kültler olmadan kültürün yaşaması neredeyse imkânsızdır. Bu açıdan kült, bir bakıma, "hafızadaki anlamlı olan kalıp veya modeldir." Alman Mısırolog Assmann'ın ifade ettiği (2015: 85, 98-99) "toplum için anlamlı olanın hatırlanacağı" varsayımı kültleş(e)memiş inanışların sonraki nesillere aktarım sorununu gündeme getirmektedir. Çünkü birinci sözlü kültür ortamında kuşaklar arası aktarımın sembollerle yapıldığı varsayılmaktadır.

İnsanoğlu, başlangıçtan günümüze kozmos arayışı içinde olmuştur. Güvenlik, bereket, bolluk ve refah gibi nitelikleri içinde barındıran kozmos düşüncesinin temelinde "uyumluluk isteği" bulunmaktadır. Dolayısıyla "insan, sadece eşyaları yaratmakla kalmaz; aynı zamanda onları yaşamaya zorlar." Eşyanın "simgesel değerinin artması" demek olan bu düşünüş biçimi, söz konusu eşyayı kült alanının içine yerleştirir. Törenler vasıtasıyla da kült zamanla kültürün bir nesnesine (Lvova vd., 2013: 195) dönüșebilir.

Kült ve kültür arasında kurulan ilk ilişkilerde, kült tanımlarında olduğu gibi, teolojik anlayışın hâkim olduğu görülür. Dine ve dinî gruplara işlevsel bakış açısı ile yaklaşan ve bu grupları bir tür "uyum modeli" olarak düşünen Eister (1972: 323, 327) için "uyumlar sözlü olarak ifade edildiğinde, modern toplumlardaki oryantasyon büyük ölçüde sözlüleștirilebilir normlarla yönlendirilen iletişim biçiminde ve sözel sembollerle ifade edilebilir". Bu aşamada kült, "ilk sözlü iletişim biçimleri" olarak tanımlanabilir.

Kült olgusuna Freud ve özellikle Jung temelli bir bakış açısıyla yaklaşan Halton (2014: 49, 72) için kült, "insan bedeninin en derin duygusal, bilinç öncesi ve içgüdüsel anlamlarını içerir"; "inanç şeklinde zirveye ulaşan ifadeye olan itkisinin bir çıkışıdır"; "kültürün en biyolojik bileşimidir" ve "ifade etme dürtüsüdür." İfade meselesini geleneksel bilgi veya sistem şeklinde gören çoğu kültür kuramcının aksine araştırmacıya göre ifadenin esası, işaret uygulamalarıdır. Bu bağlamda dil, jest, imaj ve yapıt gelenekleri

11 Örneğin, günümüzde anlatanı ve dinleyicisi olmayan dillere "ölü diller" denilmesi bağlama gönderme yapan bir tanımlamadır. 
ifadenin amaçları olarak değil, "cisimleşmiş işaret uygulamalarına yönelik araçlar” biçiminde görülmelidir. Bu cümleden kültler, sıradan içgüdüsel dürtüler değil; kültür içinde iletişim ortamı sağlayan aracılar konumuna yükseltilmektedir.

Kültsel uygulamaların ilkel kültürlerde bir iletişim aracı olarak nasıl hizmet ettiğini anlamaya çalışan Jensen'in belirttiği gibi (1963: 42-43), topluluk içinde yaşamını sürdüren insanoğlu, tüm önemli kaygı ve ilgilerini iletebileceği bir iletişim aracına ihtiyaç duymuştur. Yüz ifadelerinin, jestlerin veya bakışların, çoğunlukla kelimelerden daha fazlasını söyledikleri dikkate alındığında kültler, "sosyal olarak tabakalandırılmamış olan homojen topluluklarda tercih edilen iletişim araçları" olmuşlardır. Dolayısıyla kültlerin sadece maddî ve manevî yönlerinden değil, aynı zamanda sosyal yönlerinden de bahsetmek gerekir. Buradan yola çlkarak kültürün kült kökenleri12, temel olarak ifade biçimlerinde; yas törenleri ve kutlama ritüellerinde; efsanevî, toplumsal ve kişisel iletişim dramlarında veya geçmişten günümüze tarım, köy ve kentler gibi kalıcı kurumlar oluşturarak "kendini temsil ettiği iletişim" uygulamalarında takip edilebilir (Halton, 2014: 85). Yani erginlenme törenleri, geleneğin kutsanmasını; yiyecek kültleri ile kurbanlar, insanın iyicil güçlerle bağ kurmasını veya cenaze törenleri, bir kişinin kaybından sonra "grubun sarsılmış dayanışmasının kurulmasını ve moralinin yeniden kazanılmasını” (Malinowski, 1990: 41-42) sağlayabilir.

Kültürün kaynağını, "daha ilkel yaşam faktörü" şeklinde tanımladığı kült (cult veya cultus) içinde arayan Vogt $(1951: 3$, 159) kültü, tarihsel ve mantıksal olarak dindeki merkez olarak görmüştür. Ona göre kült, tüm dinî elementleri içerir, organize eder ve işletir. Bu cümleden külte teolojik olarak yaklaşan araştırmacı din olgusunu, sosyal bir biçim olarak kültürün başlıca kaynağı saymakla kültü sosyal birliğin (topluluğun) bağlamına taşımıştır: "Sosyal bir biçim olarak kültür, dinî bir biçim olarak kültten türemiştir. Kült, halk ibadetinden oluşan dinî faaliyetler sistemidir. Dindeki merkezdir, dinî tecrübedir ve davranıştır. Bu davranışın dıştaki ifadesi külttür. Kültün üstünlüğü, hem mantıksal hem de tarihseldir" (Vogt, 1951: 154). Kültler, bilhassa teolojik çalışmalarda ön planda yer almışlardır. Bu yüzden onlar, "ilk zamanların büyük dinî dili" (Jensen, 1963: 42-43) olarak görülmüştür.

Kültü, ritüel eylemlerinin gerçek ve nesnel pratik sonuçları olarak düşünen Vogt'a göre (1951: 168) "kült, geçmişin ürünlerini koruyan belli bir yapıdır." Toplumun geleneğini veya gelenekselliğini sürdürme işlevini yerine getiren bu yapının oluşumundaki işlevsel süreç kalıplaşma, varyantlaşma ve gelenekselleşme ile birlikte meydana gelir. En nihayetinde

12 Kadın ve erkek biçimindeki toplumsal cinsiyet kimliği algısının oluşumuna ilișkin fikirlerin kültik kökenlerine dair yapılan çalışma için bk.: (Poliakova ve Asotskyi, 2019). Bu makale, kişilik dönüşümü pratiğinin fenomenolojisini toplumsal cinsiyet kimliği hakkındaki fikirlerin psiko-psikolojik temeli olarak incelemektedir. Bu incelemenin temel çıkıs noktasını ise Dionysos kültü oluşturmaktadır. 
de kült olarak tanımlanan bu model/yapı/şablon, kültürün nesnesine dönüşür.

Bir nesnenin kültür unsuruna dönüşüm sürecinde sanat ayrı bir yerde bulunmaktadır. Örneğin, teolojik yaklaşıma sahip olan Vogt (1951: 162-163) gibi araştırmacılara göre şarkılar, danslar, taklitsel hareketler, dekorlar, kostümler, bunların tamamı kültürel sanat olmadan önce dinî sanatın birer parçasıydılar. Bunun yanı sıra özellikle ritüel-sanat ilişkisinde "tekrarlanan sunum" dikkate değerdir ve bu süreçte "ritüelden sanata" geçiş sağlayan bir tür "soyutlama" meydana gelir (Harrison, 1913: 42). Ritüelden sanata doğru olan bir değişimin olduğu varsayılabilir. Aynı varsayım kültten kültüre de uygulanabilir. $\mathrm{Bu}$ bağlamda kültürü derinlemesine anlayabilmek veya kültürün oluşum aşamalarını anlamak için kültlere bakmak gereklidir; ancak kült ve kültür arasında bir gelişim veya evrimden ziyade bir "ilişki" olduğu vurgulanmalıdır.

Kült, kültür ve sanat arasındaki ilişki bağlamında Flood'un (2002: 652) şu ifadeleri dikkate değerdir: "Kült simge ile sanat nesnesi arasındaki ayrım, Batı epistemolojisinde eski bir konu olup tarihsel bakımdan, ikon düşmanlığı eylemlerine karşı bir savunma olarak öne sürülme eğiliminde olduğundan, bir çeşit putperestlik mekânı olarak müze fikri saçma görünebilir13. Dahası, müze kurumunun kendisi, 'kültten' -Batı'da moderniteye geçişi en azından XVIII. yüzyıldan itibaren indeksleyen'kültüre' geçişin bir göstergesidir." Müzelerin, kültten kültüre geçişin somut mekânları olabileceği düşüncesi, kült ve kültür arasındaki bağlantıyı güçlendirmektedir. Bu noktada "kültün bağlamı" ön plana gelmekte ve şu sorular cevaplanmayı beklemektedir:

Kült ikonu/simgesi (cult icon) ve sanat objesi (art object) arasındaki fark nedir? Kült nesneleri, bağlamını yitirdiklerinde kültüre mal oluyor olabilir mi? Kültlerin özündeki "tapma veya aşırı saygı duyma, ululama, kutsama" (adore, veneration) gibi duygusal bağlanmalar, zaman ve mekâna göre değișim gösterdiğinde bağlamından kopuyor olabilir mi? Bu durumda eskilerin kült objeleri -bağlamını kaybettiği için- günümüzün maddi-kültürel nesnesi haline geliyor olabilir mi?

\footnotetext{
13 Erken modern Avrupası'nda "dinî simgenin sanat nesnesine dönüşümü" üzerine Belting'in (1994) yaptığı bir çalışma, anlamlarını en iyi şekilde kullanımlarıyla ortaya koydukları inanmalar üzerine odaklanır. Burada simgeler veya görüntüler açıklanmaya çalışılmaz. Belting (1994: xxii), ele aldığı imajlarda insanlar ile onların inançları, batıl inançları, umutları ve korkularıyla ilgilenir. Fakat tüm bunlarla birlikte çalışmada "kült" kelimesi için, hiçbir sözlükte olmamasına rağmen, "varlık" veya "varoluş" (presence) karşıllğı verilmiştir. $\mathrm{Bu}$ tercihle yazar, inançlar, batıl inançlar ve görüntülerdeki umut ve korkuların "bir dönemin gerçekliği" olarak algılandığına vurgu yapmıștır. Yani, bugün bir sanat eseri ve "uniquie eser" olarak kabul edilen birçok yaratının, ortaya çıktığı veya yapıldığı dönemlerde "gerçekliğin ta kendisi" olarak algılandığı gösterilmiştir. Bu gerçeklik algısı ise konumuz bağlamında dikkate değerdir.
} 
Tüm bu sorgulamalarla birlikte müzedeki bir eserin yeniden boyutlandırılmasının, onun işaretleme yaradılışındaki değişim olarak gören çalışmalarda bu değiş̧imin, "kült sembolden kültürel ikona geçiş" Flood, 2002: 653) olarak görülmesi dikkate değerdir. Söz konusu açılamalardan hareketle şunu söylemek mümkündür: Dini imaj bağlamını kaybettiğinde kültün değil, kültürün bir nesnesi haline gelmektedir. Başka bir deyişle, bir dönemin oldukça işlevsel olan nesneleri günümüzde başka işlevler kazanarak, çoğu zaman, kültür nesnesi/unsuru olarak yaşamaya devam etmektedirler. Bu işlevsellik bazen bir düşünce tarzı, bazen bir inanış biçimi, bazen de kendisi olarak maddî bir unsur olabilmektedir.

\section{Kültten Kültüre: Kült Tipolojisi Üzerine Bir Deneme}

Araştırmacılar tarafından geliştirilen birkaç model, geç modern toplumdaki yeni dinlerin manzaralarını ortaya çıarmaya yardımcı olmuştur. Bunlardan biri olan "görünmeyen düzen" (unseen order) modeli, din hayatının temelindedir. Böyle bir inanç sisteminde temel amaç, "görünmeyen düzen ile uyumlu bir uyum" sağlamaktır. Bu bağlamda herhangi bir dinî gelenekte bu görünmeyen düzen tasavvuru, temelde dinî mitlerin, inançların ve belli açıklayıcı anlatıların gelişmesini harekete geçirir (Cowan ve Bromley, 2015: 8-9). Bununla birlikte bu mitik anlatılar, takipçileri görünmeyen düzene bağlayan öngörülen davranışlarda, dinî ritüellerde ve pratiklerde yansitılır. Böylece söz konusu görünmeyen düzenin gerçekliği ve gücü ortaya çıkar. Dolayısıyla kült içinde tanımlanan hareketler, benzerleri içinde -diğer kültür unsurlarından veya sosyolojik olarak diğer dinî gruplardan- ayrılırlar. Bunların kendi mitlerine, inançlarına ve ritüellerine özgü vurguları, bir grubu veya kültür unsurunu kült olarak tanımlamada belirleyicidir.

Çoğu gelenekte dinî toplulukların mitik ve ritülelistik sistemlerin prensipleri etrafında düzenlendikleri (Cowan ve Bromley, 2015: 10) varsayımı dikkate alındığında modern toplumda ortaya çıkan yeni dinî geleneklerin, kadim inanç ve uygulamalar üzerinde şekillendiklerini söylemek mümkündür. Bu bağlamda sosyolojik bağlamda modern toplumun kült veya zaman zaman sect olarak tanımlanan örgütlerini-gruplarını anlayabilmek için mit biliminde sıklıkla geçen "kült" olgusuyla işe başlamak gerekmektedir. Buradan hareketle mit araştırmaları bağlamında kültün bileșenlerini aşağıdaki gibi sıralamak mümkündür14:

$14 \mathrm{Bu}$ sıralama Pavlos'un The Cult of Experience adlı çalışmasında yer alan yeni dinî hareketlerin dinî bir kült grubu oluşturup oluşturmadıklarının belirlenmesi için sıralanan kıstaslardan yararlanılarak oluşturulmuştur. Daha ayrıntılı bilgi için bk.: (Pavlos, 1964: 4). Türk kültürü ve mitleri bağlamında kültün tanımlanması ile ilgili olarak Ocak'ın kıstasları "külte konu olabilecek bir nesne veya şahsın mevcudiyeti; bu nesne veya şahıstan insanlara fayda veya zarar gelebileceği inanışı; bu inanıșın sonucu olarak faydayı kendine çekme, zararı defedecek ziyaretler, adaklar, kurbanlar ve benzeri uygulamaların varlığı" olmak üzere üç noktada belirlenmiştir. Bununla birlikte söz konusu sınıflama günümüz mit bilimindeki kültler hakkında yeterli bir açıklama sunmadığından Ocak'ın tasnifinden de yola çıkılarak öneride bulunulmuştur. Daha ayrıntılı bilgi için bk.: (Ocak, 2002). 
- Kült yaratıcıları ve aktarıcıları, kültün içinde yer aldığı kültürü aktaran kişiler ${ }^{15}$,

- Kültlerde yaratıcı ve aktarıcıların etkisi16,

- Kültlerin kurulan düzenin devamını sağlaması ve gelenekselliği ${ }^{17}$,

- Kültik hareketin icrasında aitlik ve rahatlama hissi, kabul edilme18,

- Külte bağlllık duyma19,

- Kültün yaşaması için gerekli olan ritüeller ${ }^{20}$.

\section{Sonuç}

Kült kavramı, mit biliminde yaygin olarak "kutsama", "tapma", "ibadet", "inanç örüntüsü" biçimlerinde açlklanırken; özellikle günümüzdeki din sosyolojisi araştırmalarında ve ilgili çalışmalarda "çoğunluğun geleneksel dini ile uyumsuz olan nispeten küçük dinî bir grup" olarak tanımlanmaktadır. Kült kavramının açıklanmasındaki bu karmaşa, "bağlam temelli yaklaşım" ile çözümlenebilir veya azaltılabilir ve buradan hareketle kültün bileşenleri saptanabilir.

Antropoloji, etnoloji, psikoloji, sosyoloji, din sosyolojisi gibi beşerî bilim dallarında kült konusunun oldukça eski bir geçmişi bulunmakla birlikte son yıllarda özellikle sosyoloji alanındaki tartışmalar daha çok "cult (kült)" ve "sect (sekt)" arasında şekillenmiştir.

Mit araştırmalarında da kültle ilgili bir karmaşa söz konusudur. Bunun sebeplerinden birisi kültün kendi içinde "worship (tapım)" ve "veneration (ululama)" veya "reverence (yüceltme)" gibi birbirine yakın ancak birkaç bakımdan farklılaşan anlamları bulundurmasından kaynaklanmaktadır. Dolayısıyla kültün yer aldığı bağlama göre ele alınması daha doğru sonuçlar elde etmeyi sağlayabilir. Bu açıdan her inanç unsurunun kült içinde değerlendirilmesi mümkün değildir. Kültleşme eğilimi gösteren inanç

15 Sosyolojik olarak kült; grup bağlamında bu kişiler yaşayan liderler, liderlerin ilgi ve ideolojileridir ve grubun başarısı liderinin bilgeliğine bağlıdır.

16 Sosyolojik olarak kült; grup bağlamında takipçileri diri tutma, aktarıcıların üyeler üzerindeki otoritesi.

17 Sosyolojik olarak kült; gruplar içinde eleștirel düșünceler yok edilir ve baskılanır.

18 Sosyolojik olarak kült; gruplar, inançlı takipçileri için kurtuluş garanti eder.

${ }^{19}$ Sosyolojik olarak kült; gruba güçlü bağlılık hissi, kült normlara veya standartlara keskin itaat talebi ve itaate uyma; grubun başarısı takipçilerin sadakatine bağlıdır.

20 Sosyolojik olarak kült; gruplarda dinî ritüellere veya meditasyona benzer teknikler vardır. $\mathrm{Bu}$ teknik, grubun üyelerini psikolojik olarak etkiler. Bununla birlikte beyinin çalışma prensipleri üzerine bağımsız araştırmalar yapan Dr. Cath ve Dr. Clark, kült gruplar içindeki monoton veya ritmik șarkı söylemek veya dans etmek gibi programlanmıș ve standartlaştırılmış hareketlerin veya birtakım ritüellerin beyinde psikofizyolojik (psychophysiological) değișikliklere neden olabileceğini düşünmektedir. Ona göre "bedenin ritmik hareketi, değişmiş bilinç durumlarına neden olabilir ve beyinin basınç veya titreşim düzenindeki bu değişiklikler, geçici lobu etkileyebilir". Bu değişimi Dr. Clark "kültdönüşümü sendromu" (cult-conversion syndrome) olarak tanımlamıştır (Collin, 1982). 
unsurlarının belli bir olgunlaşma süresinin (kalıplaşma, varyantlaşma ve gelenekselleşme) olduğuna dikkat çekilmelidir.

Yapısal ve işlevsel açıdan kültlere yaklaşıldığında, onları oluşturan inanç unsurlarının üç temel yapısının olduğu ortaya çıkmaktadır. Bunlardan biri onun maddî (gerçek, fizikî, tabiata ilişkin) anlamı; diğeri manevî (psişik, mitik, mistik, sihrî, kutsal, mecazî) anlamı ve bir diğeri davranışlarla oluşan toplum içindeki sosyal anlamıdır. Maddî taraf onun toplum hayatına ilişkin işlevi ile ilgiliyken; manevî tarafı mitik anlatısında görülmekle beraber onun insanda uyandırdığı ruhî veya psişik tarafı ile ilgilidir. Sosyal tarafı ise insanlar arasında ilişki kurulmasını sağlayan toplum içindeki iletişimsel ve semboller dizgesi olması durumudur. Bu üç temel olgu mevcut olduğunda külte konu olan inanç unsurunda kalıplaşma, çeşitlenme ve gelenekselleşme meydana gelmekte, böylece söz konusu inanış biçimi kült sınıfı içine girmektedir. Dolayısıyla kült sınıfı içinde yer alacak nesnelerin veya şey'lerin gerçek dünya veya yaşam ile doğrudan ilişkileri olup grubun onları kabul edip-etmemeleri onların yaşam sürelerini belirlemektedir.

Bir inanç nesnesi çeşitlenip etki alanını genişlettikten sonra görünüş gibi bazı noktalarda kalıplaşır ve bir süre sonra gelenekselleşme eğilimi gösterir. "Kültlerin oluşum süreci" bağlamında zamanla kült etrafındaki bu çeşitlenmeler, kalıplaşmalar ve gelenekselleşmeler onun kültür yaratmasına zemin hazırlar. Burada gelenekselleşme konusu ise tartışmaya açıktır. Bazen varyantlaşma ve kalıplaşma da inancın külte dönüşmesi için yeterli olabilir. Dolayısıyla kültte geleneksellik olduğu veya gelenekselleşme sağlandığı zaman bugün anladığımız manada bir "kültür"den bahsedilebilir.

Kültürel belleğin yapısını oluşturan kültürel genetik kodların canlı bir şekilde yaşatılmasında onun görsel, işitsel ve duyusal anlamda sembolleştirilmesi belleğin işleyişini anlamak açısından önemlidir. Bunu mümkün kılan en güçlü sistemin kült ve ona bağlı ritüeller olduğu söylenebilir. Diğer bir deyişle, mit bağlamı içinde, en arkaik iletişim biçimleri kültlerdir. Kültlerin içinde yer alan ritüeller de kültlerin hayatta kalmasını sağlar. Arka planda yer alan ruh düşüncesi, ruhlarla iletişime geçme ihtiyacı, bunun için kullanılan çeşitli araçlarla birlikte yapılan uygulamaların her biri bu iletişimin diğer boyutlarıdır. Dolayısıyla insanoğlunun ilk iletişim biçimleri, kültlerde ortaya çıkmış olmaktadır.

Kültlerin araştırılması demek kültürlerin kimliklerinin araştırılması, onları birbirinden ayıran ve birbirine yaklaștıran unsurların tespit edilmesi ve böylece arka planlarını anlamak demektir. Tanımlamalarında görüldüğü üzere kültür, insanların yapıp etmeleri sonucunda ortaya çıkan, gelişen ve dolayısıyla üretilen bir semboller dizisidir. Bu üretimin en ilksel ve arkaik biçimini kültlerde bulabilmekteyiz. Bu açıdan kültleri araştırmak, anlamak, anlamlandırmak ve çözümlemeye çalışmak "ilk ve en eski kültür kalıntılarını" gün yüzüne çıkarmak anlamına gelmektedir. 
Sonuç olarak mit araştırmalarında sıklıkla kullanılan kült teriminin bütüncül bir bakış açısıyla yeniden ele alındığı bu çalışmada alana yeni bir kült tanımlaması önerilmiştir. Buna göre kült, benzerleri içinde ayrılan; maddî, manevî ve sosyal yönleri olan; mit ve ritlerle aktarılan; kutsal olduğuna inanıldığından gönüllü bir bağlllık duyulan; arkaik geçmişle bağlantısı sebebiyle varyantlaşırken kalıplaşan ve gelenekselleşen ve bünyesindeki uyarlanma sayesinde kendini sürekli yenileyen bir inanış örüntüsüdür. Bu örüntü, genel olarak, mitlerin ve ritüellerin bölünebilen en küçük parçasıdır.

Tüm bunlarla birlikte kültü yapısal ve işlevsel yönden ele almak, günümüzün modern kültlerini ve mitlerini açıklama noktasında yardımcı olabilir. Bu çalışma, kült üzerine yapılacak yeni çalışma ve tartışmalara bir giriş niteliğindedir.

\section{KAYNAKÇA}

\section{Yazılı Kaynaklar}

AKYURT, Metin (1998). M. Ö. 2. Binde Anadolu'da Ölü Gömme Adetleri. Ankara: Türk Tarih Kurumu Yayınları.

ASSMANN, Jan (2015). Kültürel Bellek: Eski Yüksek Kültürlerde Yazı, Hatırlama ve Politik Kimlik. İstanbul: Ayrıntı Yayınları.

BARKER, Eileen (1986). "Religious Movements: Cult and Anticult since Jonestown". Ann. Rev. Sociol., 12, 329-346.

BELTING, Hans (1994). Likeness and Presence: A History of the Image before the Era of Art. (Trans.: Edmund Jephcott), Chicago and London: The University of Chicago Press.

BUSS, Martin J. (1964). "The Meaning of "Cult" and the Interpretation of the Old Testament". Journal of the American Academy of Religion, 4, 317-325.

COWAN, Douglas E. and BROMLEY, David G. (2015). Cults and New Religions: A Brief History. Oxford: Wiley Blackwell Pub.

ÇOBANOĞLU, Özkul (2001). "Ata”. Türk Dünyası Edebiyat Kavramları ve Terimleri Ansiklopedik Sözlüğü I, Ankara: AYK Atatürk Kültür Merkezi Başkanlı̆̆ı Yayınlarl.

DAVIS, Dena S. (1996). "Joining a Cult: Religious Choice or Psychological Aberration". J.L. \& Health, 11, 145-172.

EDARA, Inna R. (2017). "Religion: A Subset of Culture and an Expression of Spirituality". Advances in Anthropology, 7, 273-288.

EISTER, Allan W. (1972). "An Outline of a Structural Theory of Cults". Journal for the Scientific Study of Religion, 4, 319-333.

FAULKNER, Quentin (1996). "Cult and Culture at the Millennium: Exploratory Notes on the New Religion". Soundings: An Interdisciplinary Journal, 79, 399-420.

FLOOD, Finbarr B. (2002). "Between Cult and Culture: Bamiyan, Islamic Iconoclasm, and the Museum". The Art Bulletin, 84, 641-659.

GEERTZ, Clifford (1973). The Interpretation of Cultures. New York: Basic Books, Inc. HALTON, Eugene (2014). "Kültürün Kültsel Kökenleri”. Kültür Kuramı, (Çev.: Cumhur Atay), İstanbul: Pales Yayıncllı. 
HARRISON, Jane E. (1913). Ancient Art and Ritual. London: Williams and Norgate.

HOLDSWORTH, Clare (2015). “The Cult of Experience: Standing Out from the Crowd in an Era of Austerity". Area, 1-7.

IBRAHIM, Murtala (2013). "The Rise and Proliferation of New Religious Movements (NRMs) in Nigeria". International Journal of Humanities and Social Science, 3, 181-190.

IBRAYEV, Şakir (2005). "Kazak Mitleri ve Mitik Efsaneleri Hakkında”. (Çev.: Metin Arıkan), Türk Dünyası Íncelemeleri Dergisi, 2, s. 353-358.

INSOLL, Timothy (2005). "Archaeology of Cult and Religion", Archaeology-The Key Concepts. (Ed.: Colin Renfrew and Paul Bahn), London and New York: Routledge.

JENSEN, Adolf E. (1963). Myth and Cult among Primitive Peoples. (Trans. M. T. Choldin and W. Weissleder), Chicago: The University of Chicago Press.

KELLY, Greg and Mcfarlane, Heather (2007). "Culture or Cult? The Mythological Nature of Occupational Therapy". Occupational Therapy International, 14, 188-202.

LARSON, Bob (1983). Larson's Book of Cults. Wheaton. Illinois: Tyndale House Publishers.

LOWERY, R. H. (1991). The Reforming Kings: Cults and Society in First Temple Judah. England: Sheffield Academic Press.

LVOVA, E. L. ve diğerleri (2013). Güney Sibirya Türklerinin Geleneksel Dünya Görüşleri-Kâinat ve Zaman, Nesneler Dünyası. (Çev.: Metin Ergun), Konya: Kömen Yayınları.

MALINOWSKI, Bronislaw (1990). Büyü, Bilim ve Din. (Çev.: Saadet Özkal), İstanbul: Kabalcı Yayınevi.

MISCALL, Peter D. (2011). "Review of Jacob Taubes, From Cult to Culture: Fragments Toward a Critique of Historical Reason, Stanford: Stanford University Press, 2010". The Bible and Critical Theory, 7, 98-100.

NEAL, Lynn S. (2011). “They're Freaks!: The Cult Stereotype in Fictional Television Shows, 1958-2008”. Nova Religio: The Journal of Alternative and Emergent Religions, 14, 81-107.

NELSON, Geoffrey K. (1969). "The Spiritualist Movement and the Need for a Redefinition of Cult". Journal for the Scientific Study of Religion, 8, 152-160.

OCAK, Ahmet Y. (2002). Alevî ve Bektaşî İnançlarının İslâm Öncesi Temelleri. İstanbul: İletişim Yayınları.

OCH, Dana (2019). “The Mainstream Cult of Fifty Shades of Grey: Hailing Multiple Women Audiences". Communication Culture \& Critique, 12, 213-229, doi:10.1093/ccc/tcz017.

OLSON, Paul J. (2006). "The Public Perception of 'Cults' and 'New Religious Movements'”. Journal for the Scientific Study of Religion, 45, 97-106.

PANAGIOTIDOU, Olympia (2016). "Religious Healing and the Asclepius Cult: A Case of Placebo Effects". Open Theology, 2, 79-91.

PANCHENKO, Alexander (2004). "New Religious Movements and the Study of Folklore: The Russian Case". Folklore, 28, 111-126.

PAVLOS, Andrew J. (1964). The Cult Experience. England: Greenwood Press. 
PFEIFER, Jeffrey E. (1992). "The Psychological Framing of Cults: Schematic Representations and Cult Evaluations". Journal of Applied Social Psychology, $22,531-544$.

POLIAKOVA, O. O. ve ASOTSKYI, V. V. (2019). "Dionysus Cult as a Prototype of Autonomous Gender". Anthropological Measurements of Philosophical Research, 15, 155-165.

RICHARDSON, James T. (1979). "From Cult to Sect: Creative Eclecticism in New Religious Movements". The Pacific Sociological Review, 22, 139-166.

RICHARDSON, James T. (1993). “Definitions of Cult: From Sociological-Technical to Popular-Negative". Review of Religious Research, 34, 348-356.

SANDWITH, Corinne (2004). "Contesting a 'Cult(ure) of Respectability': AntiColonial Resistance in the Western Cape, 1935-1950". Current Writing: Text and Reception in Southern Africa, 16, 33-60.

SERED, Susan S. (1995). "Rachel's Tomb: The Development of a Cult". Jewish Studies Quarterly, 2, 103-148.

SEYMOUR-SMITH, Charlotte (1987). Macmillan Dictionary of Anthropology. London: The Macmillan Press Ltd.

SHILS, Edward (2003). “Gelenek”. Doğu Batı Düşünce Dergisi, 25, s. 101-131.

SHTERIN, Marat and RICHARDSON, James T. (2000). "Effects of the Western AntiCult Movement on Development of Laws Concerning Religion in PostCommunist Russia". Journal of Church and State, 42, 247-271.

SMITH, Philip (2007). Kültürel Kuram. (Çev.: Selime Güzelsan ve İbrahim Gündoğdu), İstanbul: Babil Yayınları.

SWANTKO, Jean A. (2000). "The Twelve Tribes' Communities, the Anti-Cult Movement, and Government's Response". Social Justice Research, 12, 341364.

VOGT, von Ogden (1951). Cult and Culture: A Study of Religion and American Culture. New York: The Macmillan Company.

WALLACE, Anthony F. C. (1956). "Revitalization Movements". American Anthropologist, 58, 264-281.

WINICK, Charles (1957). Dictionary of Anthropology. London: Peter Owen Limited.

YILDIRIM, Dursun (1991). “Türk Folklor Araştırmalarının Problemleri”. Millî Folklor, 11, s. 13-21.

YOSHIHIDE, Sakurai (2000). "Cult Controversy and Anti-Cult Movement in Japan since 1995: Case Study of a New Religions Cult, The Tenchi-Seikyo, Affiliated with the Unification Church". The Annual Report on Cultural Science, 101, 193226.

\section{Elektronik Kaynaklar}

COLLIN, Glenn (1982). "The Psychology of the Cult Experience”. The New York Times, https://www.nytimes.com/1982/03/15/style/the-psychology-of-the-cultexperience.html (Erişim: 10/11/2019).

EDWARDS, Ben (2018). "What is a Cult?”. Detroit Baptist Theological Seminary, https://dbts.edu/2018/11/16/what-is-a-cult/ (Erişim: 06/11/2019). 